\title{
Reliability and validity of a measure of work-related subjective experiences among people with psychiatric disabilities
}

Geoffrey Waghorn, Meredith G Harris, Beverly Gladman, Nicole Hennessey, Chris Lloyd, Bryan Mowry

Aims: To investigate aspects of the reliability and validity of the Work-related Subjective Experiences Scale (WSE-38), an instrument designed to help mental health professionals tailor mental health care to reduce employment restrictions.

Geoffrey Waghorn

is Head of Social

Inclusion and

Translational Research,

the Queensland Centre

for Mental Health

Research. He holds an

adjunct appointment

as Senior Lecturer,

The University of

Queensland, The School

of Population Health;

Meredith G Harris

is Senior Research

Fellow, The University

of Queensland, School

of Population Health;

Beverly Gladman is

Research Officer, The

Queensland Centre for

Mental Health Research,

Policy and Economics

Group, The Park Centre

for Mental Health;

Nicole Hennessey is

Research Officer, The

Queensland Centre for

Mental Health Research,

Policy and Economics

Group, The Park Centre

for Mental Health;

Chris Lloyd is Senior

Occupational Therapist,

The Gold Coast Mental

Health Service, Ashmore;

and Bryan Mowry is

Director, Queensland

Centre for Mental Health

Research, Genetics

Group, The Park Centre

for Mental Health, and

Professor, Department

of Psychiatry,

The University of

Queensland, Queensland, Australia

Correspondence to: $G$ Waghorn

E-mail: geoff_waghorn@ qcmhr.uq.edu.au

Methods: Sixty community residents with schizophrenia or schizoaffective disorder were recruited from a register of previous research participants in an existing genetics study of people with schizophrenia. The WSE-38 was administered via telephone interview, repeated two-five days later. Short-cycle test-retest reliability, internal structure, and concurrent validity were assessed. Face validity, utility, consumer and clinician acceptability were examined qualitatively.

Findings: Short cycle test-retest reliability for most items and the total score were found to be good to very good. Items with low reliability were removed. Concurrent validity was promising with respect to a range of relevant measures. Face validity, client acceptability, and user utility were adequate. Further scale development and modifications to administration instructions are indicated. Conclusions: These results support further scale development and inform how it can be used for its intended purpose. Sensitivity to real change and predictive validity require ongoing investigation.

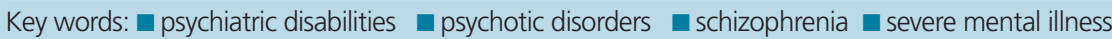
च supported employment $\quad$ vocational rehabilitation

Submitted 19 July, sent back for revisions 27 August; accepted for publication following double-blind peer review 6 September 2010

he social cognitive career theory provides a framework for explaining career development among people with psychiatric disability (Fabian, 2000). According to this theory, personal characteristics, illness characteristics, and environmental factors combine to shape individual career learning experiences. Examples of environmental factors are the availability of appropriately intensive employment assistance (Bond et al, 2008), and the availability of suitable performance opportunities. Examples of personal characteristics are self-assessments of capacity to work, and expectations of success in employment. Subjective experiences of mental illness have been found to be more useful than diagnostic symptoms for identifying how mental illness impacts on a person's perceived employment capacity (Waghorn et al, 2005a; 2007a).

In theory, work-related subjective experiences arise at the trisection of individual characteristics, illness symptoms, and work performance expectations (Waghorn et al, 2005a). Prior investigations of subjective experiences and cognitive complaints suggest that these can explain a wide range of functioning difficulties (Liddle and Barnes, 1988; Hatfield, 1989). Consistent with these conclusions, work-related subjective experiences were found to be consistently related to work-related self-efficacy and to current vocational status in a 12-month longitudinal study (Waghorn et al, 2005a; 2007a). This fits within the social cognitive career theory because work-related subjective experiences are expected to mediate the relationship between past career learning experiences and efficacy beliefs (Fabian, 2000).

If reliable and valid, measures of this construct have potentially useful applications in psychiatric rehabilitation and supported employment, by enabling the nature of current perceived experiences that result in work-restrictions, to be identified. By identifying the key subjective experiences that contribute to specific employment restrictions, it is expected that health professionals will be able to identify new forms of assist- 
ance or design health interventions to reduce the impact of health conditions on perceived ability to work (Waghorn et al, 2008).

The Work-related Subjective Experiences Scale (WSE-38) uses 38 candidate subjective experiences that were selected through being frequently self-reported as personal barriers to employment. Previous investigations of construct validity, factor structure, responsiveness, internal consistency, stability over 12 months, long cycle testretest reliability (28-35 days), and criterion validity with respect to 20 related measures have produced favourable results in a sample of community residents with schizophrenia $(n=104)$, where $26 \%$ of the sample were employed (Waghorn et al, 2005a). Another report has shown how work-related subjective experiences correlate with overall work-related self-efficacy, which in turn relates to current vocational status as predicted by self-efficacy theory (Bandura, 1997; Waghorn et al, 2007a). A more recent study has shown that work-related subjective experiences are reliably reported by college students without substantial health conditions. The scale was also sensitive to the stress levels reported by college students, many of whom worked in part-time employment, with similar average hours to people with psychiatric disabilities (Waghorn et al, 2008). This result is important because it supports more general applications of the measure to healthy adults, those in remission, people with other types of psychiatric disorders (e.g. affective and anxiety disorders), through to those with psychotic disorders currently experiencing psychotic symptoms.

Further investigations of short-cycle testretest reliability, discriminant validity, and predictive validity were previously recommended (Waghorn et al, 2005a). The measure was developed from both classical test theory (CCT) and item response theory (IRT) perspectives. IRT principles (Palm and Strong, 2007) were previously applied in selecting the current item set (Waghorn et al, 2005a) based on a balance between properties of responsiveness and stability at an item level. While the aim was to capture subjective experiences that are most related to perceptions of difficulty in employment, the intent was not to capture experiences so transient that they could not be reliably reported over short time intervals (e.g. 2-5 days). A CTT approach was used to examine test-retest reliability (Thorndike, 2001) at the whole scale and item-levels because it was intended that each item could be used to inform the design of specific interventions to ameliorate particular subjective experiences, if identified as a specific barrier to a particular aspect of employment.

Reliability as a telephone interview was examined because this is considered important for use in settings where contact with clients is often maintained by telephone. Rey et al (1987, p 232) note that 'reliability is more than just consistency, that it is consistency achieved in the face of adversity'. Test-retest reliability was assessed by telephone with community residents with schizophrenia and schizoaffective disorders. These are the psychiatric diagnostic categories most challenging to reliability because of the severe cognitive, affective, and perceptual impairments so often associated with these disorders.

\section{Aims}

The aim was to investigate the test-retest reliability, internal structure, concurrent validity, face validity, client acceptability, and utility of the WSE-38 when administered as a telephone interview.

\section{METHODS}

\section{Sampling}

Ethics approval for the study was obtained from the West Moreton and Darling Downs Human Research Ethics Committee. Eligible candidates were identified from among participants in a large-scale USA-Australian collaboration called the Molecular Genetics of Schizophrenia, Part 2 (MGS2; Sanders et al, 2008) which had recently completed formal diagnostic assessments of 816 adult participants from the greater Brisbane region. This cohort is considered a large and representative sample of adult urban residents with schizophrenia, nearly equivalent in size to a previous national survey of psychotic disorders (Jablensky et al, 1998; n=980). A subsample of 374 candidates was identified from among those of working age who had participated in a subsequent study of role functioning, and who had consented to be contacted for further research opportunities. Eligible candidates from this subgroup were then systematically contacted ( 82 people were contacted) until 60 verbally consenting people meet- 
ing inclusion criteria had completed both telephone interviews.

Inclusion criteria were:

A DSM-IV diagnosis of schizophrenia or schizoaffective disorder (American Psychiatric Association, 1994)

Of working age (18 to 65 years), and

Identified as previously undertaking, or having an interest in employment or formal study, in the previous study of role functioning.

The latter criterion ensured the sample included sufficient people with employment or study goals. Exclusion criteria were:

Currently in hospital or acutely unwell, or

Not able to be contacted, or

Did not provide informed verbal consent when contacted.

Eligible candidates were contacted by one of two trained researchers. In all cases except one, the same researcher completed both interview protocols, which included demographic information, the standardized measures, and open ended questions about the measures, required for face validity and service-user acceptability.

It was not considered necessary to restrict sampling to people with a recent work history for several reasons. Firstly, the measure has been developed for the purpose of helping people into employment who may have little or no work history. Secondly, the promising psychometric properties to date have been established using a sample of community residents, including a substantial proportion of people with no recent employment experiences. This can require people to make judgments about the impact of subjective experiences on hypothetical employment despite no recent reference experiences. This is not considered problematic because of the accumulating psychometric evidence to date, particularly the stable relationships among work-related subjective experiences, work-related selfefficacy, and employment status (Waghorn et al, 2007a). Fewer subjective experiences perceived to limit employment when employed, were consistently associated with greater work-related self-efficacy, which in turn was positively associated with current employment. Hence, limiting the reliability study sample to those with a recent employment history, would needlessly limit generalizability by excluding use among people most in need of supported employment programmes, namely those with no recent work history.

Another important sampling issue is that the measure was designed to capture sub- jective experiences perceived to be a barrier to employment, because even if these perceptions are imaginary and had no basis in recent experience, they are potentially important due to their theoretical and empirical links to work-related self-efficacy (Waghorn et al, 2005a). Work-related selfefficacy in turn is correlated with actual employment and is expected to indicate how much assistance a person is likely to need through the core activities involved in returning to employment (Waghorn et al, 2005b; 2007a, 2008).

\section{Diagnostic procedure}

Ethics approval and informed consent permitted access to the diagnostic records compiled by the Molecular Genetics of Schizophrenia research team. All participants were assessed by a rigorous diagnostic protocol administered and videotaped by trained clinicians using a standard semistructured psychiatric research diagnostic interview, the Diagnostic Interview for Genetic Studies 2.0 (DIGS; Nurnberger et al, 1994). Two research psychiatrists independently reviewed all information (DIGS, Family Interview Guide for Genetic Studies, narrative reports, medical records, and videotapes where necessary). Participants in this study were a subgroup of those assigned a consensus best-estimate diagnosis (Leckman et al, 1982) of schizophrenia or schizoaffective disorder.

\section{Telephone interviews}

Minimal modifications were made to the grammar of the WSE-38 scale instructions for use by telephone. The first telephone interview commenced with a request for verbal consent and, if provided, was followed by structured questions about age, sex, country of birth, language spoken at home, marital status, number of dependent children, age left school, highest year of secondary schooling completed, postschool qualifications, and usual accommodation. Administration of the WSE-38 followed, along with four other brief measures currently being developed that are being reported separately. These measures covered: role functioning (Socially-valued Role Classification Scale, Waghorn et al, 2007b); community participation (Activity and Participation Questonnaire, Stewart et al, 2010); education-related self-efficacy (Education Self-efficacy Scale, Harris et al, 
2010); and work-related self-efficacy (Workrelated Self-efficacy Scale, Waghorn et al, 2005b, 2007a).

Other than by increasing the total interview duration, the administration of the other measures did not appear to impact on the administration of the WSE-38. A second telephone interview repeating administration of the WSE-38 and the other four measures was conducted between two and five days later. The mean duration between interviews was three days $(\mathrm{SD}=1.2)$. Upon completion of the second interview, participants were mailed a \$AU50.00 gift voucher as compensation for their time.

\section{Subjective experiences}

Individuals were asked to consider each of the WSE-38 items which represent specific examples of subjective experiences, and rate each for: (1) whether they also had that experience, or not, in the past six months, and if so, (2) the extent that each experience, when present, would impact on their ability to work, whether they are currently employed or not. Confidence in ability to work normally, when that experience is present, is then rated on an 11-point Likert-type scale, from $0 \%$ (no confidence) to $100 \%$ (total confidence) in $10 \%$ intervals. Subjective experiences not experienced in the past 6 months were considered equivalent to experiences rated as having no impact on the ability to work normally.

A previous investigation has shown the WSE-38 to have a coherent internal structure, good responsiveness, internal consistency, stability, and criterion validity (Waghorn et al, 2005a) when used by people with schizophrenia or schizoaffective disorder. The measure also generalized well to working-age students without specific health conditions. Among this group the measure showed moderate criterion validity, good test-re-test reliability, and good internal consistency (Waghorn et al, 2008).

\section{Analysis}

Two of 62 cases were removed due to poor credibility of information. Response credibility was rated to three levels by interviewers on completion of each interview, and only two cases were considered 'definitely not credible' due to an obvious and consistent response bias (e.g. responding to WSE-38 questions in exactly the same way without any sign of giving each independent thought).
Test-retest reliability was assessed by the two-way mixed effects model, single measure with absolute agreement, Intra-class Correlation Coefficient (ICC; Shrout and Fleiss, 1979) for continuous measures. The kappa statistic $(\kappa)$ was used for dichotomous items (Cohen, 1960). Reliability coefficients were calculated at the item level, as well as for subscale and total scores, as applicable. As recommended by Landis and Koch (1977), kappa coefficients of $\leq 0.20$ were regarded as poor, $0.21-0.40$ as fair, 0.410.60 as moderate, $0.61-0.80$ as good, and $\geq 0.81$ as very good. As ICC has been shown to be mathematically equivalent to weighted kappa (Fleiss and Cohen, 1973), the Landis and Koch (1997) guidelines were used to interpret the ICCs.

To confirm the relationships among variables as previously reported by Waghorn et al (2005), factorial analysis by the principal component method was used. The internal structure of the measure was explored by Cronbach's alpha analysis (Cronbach, 1990). Item level distributions were examined for

\section{Table 1.}

Socio-demographic and diagnostic characteristics at first interview $(n=60)$

Socio-demographic and diagnostic characteristics

Male

n (\%)

Age in years, mean $(\mathrm{sd})$, range

DSM-IV primary diagnosis Schizophrenia

Schizoaffective disorder $\quad 5(8)$

Age left school in years, mean (SD), range

37 (62)

$41(10.1), 23-62$

$55(92)$

Highest year of secondary school completed

Year 8

$16(1.4), 14-21$

Year 9

$4(7)$

$7(12)$

Year 10

$17(28)$

Year 11

$3(5)$

Year 12

$29(48)$

Attained post school qualification $39(65)$

Country of birth Australia 53 (88)

English speaking country ${ }^{1} \quad 3(5)$

Non English speaking country $\quad 4$ (7)

Language other than English spoken at home

$4(7)$
$2(3)$

Single marital status

$47(78)$

Dependent children living at home 1-4 children

$7(12)$

$53(88)$

Living arrangements

Family home

$14(23)$

Own home

$13(22)$

Rented home (rent not subsidised by Government) $11(18)$

Rented home (rent subsidized) 16 (27)

Hostel

$1(2)$

Homeless or no fixed address

$1(2)$

Other

$4(7)$

Notes: ${ }^{1}$ ncludes Canada, Ireland, New Zealand, South Africa, United Kingdom, USA. 
excessive skewness and kurtosis. Concurrent validity was assessed by correlating the WSE-38 score with employment-related components from the other measures administered. Analyses were conducted using SPSS for Windows version 15.0. Face validity,

Table 2.

Test-retest reliability of the WSE-38 $(n=60)$

\begin{tabular}{|c|c|c|c|}
\hline \multicolumn{2}{|c|}{ WSE-38 Item/Total } & \multirow{2}{*}{$\begin{array}{l}\text { (kappa) } \\
0.76^{\ddagger}\end{array}$} & \multirow{2}{*}{$\begin{array}{l}\text { (ICC) } \\
0.79^{\ddagger}\end{array}$} \\
\hline 1. & Too many thoughts & & \\
\hline 2. & Bewildered & $0.63^{\ddagger}$ & $0.66^{\ddagger}$ \\
\hline 3. & Poor judgment & $0.52^{\ddagger}$ & $0.66^{\ddagger}$ \\
\hline 4. & Too indecisive & $0.56^{\ddagger}$ & $0.61^{\ddagger}$ \\
\hline 5. & Forget what I was saying & $0.69^{\ddagger}$ & $0.84^{\ddagger}$ \\
\hline 6. & Difficulty correcting my mistakes & $0.25 *$ & $0.21 *$ \\
\hline 7. & Difficulty thinking of something to say & $0.47^{\ddagger}$ & $0.52^{\ddagger}$ \\
\hline 8. & Can't recall details & $0.51^{\neq}$ & $0.62^{\ddagger}$ \\
\hline 9. & Difficulty understanding people & $0.43^{\dagger}$ & $0.48^{\ddagger}$ \\
\hline 10. & Difficulty learning new things & $0.47^{\ddagger}$ & $0.57^{\ddagger}$ \\
\hline 11. & Forget the major issue & $0.53^{\ddagger}$ & $0.65^{\ddagger}$ \\
\hline 12. & Too irritable & $0.50^{\ddagger}$ & $0.73^{\ddagger}$ \\
\hline 13. & Worried about money & $0.69 \neq$ & $0.76^{\ddagger}$ \\
\hline 14. & Feeling constant pain & $0.58^{\ddagger}$ & $0.74^{\ddagger}$ \\
\hline 15. & Feeling worried, nervous or afraid & $0.60^{\ddagger}$ & $0.83^{\ddagger}$ \\
\hline 16. & Body feels weak & $0.53^{\ddagger}$ & $0.48^{\ddagger}$ \\
\hline 17. & Too inactive & $0.60^{\ddagger}$ & $0.63^{\ddagger}$ \\
\hline 18. & Hard to get started in the morning & $0.51^{\ddagger}$ & $0.54^{\ddagger}$ \\
\hline 19. & Feeling hopeless & $0.59^{\ddagger}$ & $0.65^{\ddagger}$ \\
\hline 20. & Low confidence & $0.52^{\ddagger}$ & $0.71^{\ddagger}$ \\
\hline 21. & Feel dead inside & $0.48^{\ddagger}$ & $0.62^{\ddagger}$ \\
\hline 22. & Bothered by unusual thoughts & $0.70^{\ddagger}$ & $0.88^{\ddagger}$ \\
\hline 23. & Bothered by unusual beliefs & $0.66^{\ddagger}$ & $0.82^{\ddagger}$ \\
\hline 24. & Bothered by unusual experiences & $0.44^{\ddagger}$ & $0.61^{\ddagger}$ \\
\hline 25. & Feeling suspicious & $0.66^{\ddagger}$ & $0.81^{\ddagger}$ \\
\hline 26. & Wanting to harm myself & $0.59 \neq$ & $0.65^{\ddagger}$ \\
\hline 27. & Missing appointments & $0.41^{+}$ & $0.49^{\ddagger}$ \\
\hline 28. & Afraid of losing self-control & $0.48^{\ddagger}$ & $0.55^{\ddagger}$ \\
\hline 29. & Things seem disconnected & $0.54^{\ddagger}$ & $0.70^{\ddagger}$ \\
\hline 30. & Problems with family or friends & $0.46^{\ddagger}$ & $0.76^{\ddagger}$ \\
\hline 31. & Uncomfortable with others & $0.60^{\ddagger}$ & $0.74^{\ddagger}$ \\
\hline 32. & Feeling isolated & $0.43^{+}$ & $0.58^{\ddagger}$ \\
\hline 33. & Worried about my appearance & $0.64^{\ddagger}$ & $0.53^{\ddagger}$ \\
\hline 34. & Difficulty talking to others & $0.49^{\ddagger}$ & $0.54^{\ddagger}$ \\
\hline 35. & Trouble recognizing people & $0.48^{\ddagger}$ & $0.22 *$ \\
\hline 36. & No one understands me & $0.25^{*}$ & $0.40^{+}$ \\
\hline 37. & Too many cigarettes & $0.86^{\ddagger}$ & $0.64^{\ddagger}$ \\
\hline 38. & Not careful to take medication & $0.81^{\ddagger}$ & $0.90^{\ddagger}$ \\
\hline Tota & score & $0.53^{\ddagger}$ & $0.92^{\ddagger}$ \\
\hline
\end{tabular}

Notes: Part 1 of the item refers to the binary decision as to whether that item is recognized as being experienced in the past 6 months or not. Part 2 of each item is the rating of confidence, on a $0-100$ scale, in intervals of 10 , in being able to work normally when that experience is present. ${ }^{*} \mathrm{P}<0.05 ;{ }^{\dagger} \mathrm{P}<0.01 ;{ }^{\ddagger} \mathrm{P}<0.001$. clinician and service-user acceptability and utility, were examined qualitatively based on comments solicited from each participant, and research interviewer observations systematically recorded during interviews.

The sample size for the ICC analyses was calculated by specifying $\mathrm{ICC}=0.41(\mathrm{mod}-$ erate agreement or better) as the minimum acceptable and assuming that ICCs on key SRCS items would fall above 0.70 (estimated from Waghorn et al, 2005). With $95 \%$ confidence and $80 \%$ power, a sample size of at least 33 would be required (Walter et al, 1998). The minimum sample size to detect a significant Cohen's kappa value of 0.40 or more with $95 \%$ confidence and $80 \%$ power was estimated at $\mathrm{n}=39$ (Sim and Wright, 2005). Minimum sample sizes for exploratory factor analysis were also examined. Sample sizes of less than 100 are usually considered inadequate as a rule of thumb (MacCallum et al, 1999). An exploratory factor analysis was guided by Preacher and MacCallum (2002) who suggest that factor analysis in small samples can be useful provided item communalities, size of factor loadings, degree of factor over determination, and amount of variance explained by each factor, are considered.

\section{FINDINGS}

\section{Participants}

Eighty two participants from the Brisbane MGS2 were identified and contacted as likely to meet eligibility criteria. Of these, interview pairs were completed with 62 (76\%). Nine people (11\%) declined to participate. A further 11 (13\%) people agreed to participate but were not available to complete both interviews during the study period. The demographic characteristics of the 60 participants are shown in Table 1. The mean age of participants at first interview was 41 years $(\mathrm{SD}=10.19$, range $23-62)$.

\section{Test-retest reliability}

Test-retest reliability for the WSE-38 was examined separately for the first part of each of 38 items, namely the binary response to whether the subjective descriptor in each item was recognized as being experienced in the past 6 months. Test-retest reliability was next examined for the second part of each item, a rating of confidence to work normally when that experience is present, on $0-100$ scale in $10 \%$ intervals, and for the 
total scale score. The binary part of each item performed with moderate test-retest reliability (mean item-level kappa $=0.55$ ) (see Table 2), reflecting the greater sensitivity of kappa to disagreement because of the binary nature of the items. The more continuous second part performed better, achieving on average good item-level reliability (mean kappa $=0.64)$. Despite some relatively low item-level correlations, the total score achieved very good test-retest reliability (0.92). This analysis indicated three items were candidates for removal (see items 6, 35 and 36 in Table 2).

\section{Internal structure}

Internal consistency as a single dimension measure was found to be very good $($ alpha $=0.95)$ at baseline. No items were identified as improving the scale if removed. A similarly high overall alpha was obtained using data from the second interview (0.96). In terms of internal structure, a three factor solution emerged as most preferred (see Table 3) because solutions with more factors (up to 9) included single item factors or lacked a similarly strong simple structure. Communalities of items to the full scale ranged from 0.18 to 0.78 , with 8 items less than 0.4 , and 12 items greater than 0.6. The proportion of variance explained by each factor was $22.7 \%$ for Factor $1 ; 17.5 \%$ for Factor 2; and $11.3 \%$ for Factor 3. Internal consistency of each factor was very good: Symptom control and relating to others (alpha=0.94); Memory and thinking (0.89); and Psychological distress (0.83).

The factor structure reported previously (Waghorn et al. 2005a) was examined using confidence ratings only and found very good internal consistency for four of the five previously reported factors: Psychological distress (0.86); Memory and decision-making (0.86); Thinking and communicating (0.82); Symptom control (0.83); and Energy management (0.54). The relatively poor internal consistency of the 'Energy management' factor may result from the smaller sample size in the current analysis $(n=60 ;$ vs. $n=104)$. The five dimensions previously reported were not replicated which indicates that the original factor structure based on item sources may be becoming blurred through progressive item removal on the basis on other aspects of reliability and stability. Hence, primary use as a unidimensional scale is recommended with a focus on individual items to generate new interventions targeting specific perceived employment restrictions.

\section{Concurrent validity}

Concurrent validity of total work-related subjective experiences with respect to role

\section{Table 3.}

Internal structure of the WSE-38

\begin{tabular}{|c|c|c|c|c|}
\hline \multicolumn{2}{|c|}{ WSE-38 items } & \multirow{2}{*}{$\begin{array}{l}\text { Factor } 1 \\
0.30\end{array}$} & \multirow{2}{*}{$\begin{array}{l}\text { Factor } 2 \\
0.65\end{array}$} & \multirow{2}{*}{$\begin{array}{l}\text { Factor } 3 \\
0.27\end{array}$} \\
\hline 1. & Too many thoughts & & & \\
\hline 2. & Bewildered & 0.25 & 0.77 & 0.34 \\
\hline 3. & Poor judgment & 0.20 & 0.78 & 0.09 \\
\hline 4. & Too indecisive & 0.36 & 0.58 & 0.25 \\
\hline 5. & Forget what I was saying & 0.37 & 0.68 & -0.01 \\
\hline 6. & Difficulty correcting my mistakes & 0.13 & 0.58 & -0.25 \\
\hline 7. & Difficulty thinking of something to say & 0.30 & 0.14 & -0.26 \\
\hline 8. & Can't recall details & 0.41 & 0.53 & -0.24 \\
\hline 9. & Difficulty understanding people & 0.36 & 0.59 & 0.09 \\
\hline 10. & Difficulty learning new things & 0.00 & 0.63 & -0.04 \\
\hline 11. & Forget the major issue & 0.60 & 0.33 & 0.07 \\
\hline 12. & Too irritable & 0.22 & 0.48 & 0.33 \\
\hline 13. & Worried about money & 0.50 & 0.39 & 0.19 \\
\hline 14. & Feeling constant pain & 0.02 & 0.38 & 0.50 \\
\hline 15. & Feeling worried, nervous or afraid & 0.41 & 0.49 & 0.49 \\
\hline 16. & Body feels weak & 0.36 & 0.42 & 0.16 \\
\hline 17. & Too inactive & 0.48 & 0.19 & 0.28 \\
\hline 18. & Hard to get started in the morning & 0.36 & 0.37 & 0.37 \\
\hline 19. & Feeling hopeless & 0.29 & 0.32 & 0.72 \\
\hline 20. & Low confidence & 0.41 & 0.57 & 0.43 \\
\hline 21. & Feel dead inside & 0.64 & 0.02 & 0.35 \\
\hline 22. & Bothered by unusual thoughts & 0.64 & 0.40 & 0.36 \\
\hline 23. & Bothered by unusual beliefs & 0.68 & 0.26 & 0.18 \\
\hline 24. & Bothered by unusual experiences & 0.68 & 0.38 & 0.28 \\
\hline 25. & Feeling suspicious & 0.61 & 0.11 & 0.46 \\
\hline 26. & Wanting to harm myself & 0.41 & -0.05 & 0.65 \\
\hline 27. & Missing appointments & 0.46 & -0.04 & 0.35 \\
\hline 28. & Afraid of losing self-control & 0.66 & 0.28 & 0.00 \\
\hline 29. & Things seem disconnected & 0.81 & 0.16 & 0.03 \\
\hline 30. & Problems with family or friends & 0.55 & 0.34 & 0.45 \\
\hline 31. & Uncomfortable with others & 0.63 & 0.31 & 0.33 \\
\hline 32. & Feeling isolated & 0.57 & 0.29 & 0.01 \\
\hline 33. & Worried about my appearance & 0.73 & -0.03 & 0.34 \\
\hline 34. & Difficulty talking to others & 0.64 & 0.34 & 0.08 \\
\hline 35. & Trouble recognizing people & 0.01 & 0.38 & 0.17 \\
\hline 36. & No one understands me & 0.53 & 0.21 & 0.28 \\
\hline 37. & Too many cigarettes & 0.08 & 0.28 & 0.31 \\
\hline 38. & Not careful to take medication & 0.00 & -0.10 & 0.70 \\
\hline
\end{tabular}


Table 4.

Concurrent validity of work-related subjective experiences with respect to relevant aspects of socially valued role functioning, work-related self-efficacy, education-related self-efficacy, and community activity and participation $(n=60)$

\begin{tabular}{|c|c|c|c|c|c|c|c|}
\hline & \multicolumn{3}{|c|}{ SRCS Employment items } & \multirow[b]{2}{*}{ WSS-37 score } & \multirow[b]{2}{*}{ ESS-40 score } & \multicolumn{2}{|c|}{ APQ6 work items } \\
\hline & Domain score & Status item & Interest item & & & Paid work & No job \\
\hline WSE-38 total score & $0.55^{\ddagger}$ & $-0.57^{\dagger}$ & $-0.52^{\dagger}$ & $0.60^{\ddagger}$ & $0.49^{\ddagger}$ & $0.46^{*}$ & -0.33 \\
\hline
\end{tabular}

functioning (SRCS), work-related self-efficacy, education-related self-efficacy (ESS40), and community participation (APQ6) are shown in Table 4. All relationships had expected strength and direction, with the greatest relative strength between workrelated subjective experiences and workrelated self efficacy.

\section{Face validity, utility and acceptability}

Eight participants expressed concern over their responses being different across time points and one participant suggested including questions about alcohol and coffee intake. Twenty five participants mentioned that they thought the questions were worded ambiguously. Thirty five participants went on to talk about self-harm, unusual thoughts, beliefs and experiences. Six of 60 participants seemed to experience difficulty understanding the questions and or needed them repeated and or re-explained. In addition, ten participants expressed some difficulty when providing confidence ratings. On the positive side, the items were observed to be successful at generating a conversation around these experiences, which may also prove useful for rehabilitation practitioners.

Interviewers noted that the instructions were sometimes challenging to explain over the telephone, and recommended revising and simplifying these further for telephone use. The two part nature of the scale was sometimes difficult to explain to participants at the first interview, but seemed easier at the second interview. Interviewers also recommended incorporating a sentence in the instructions to prepare participants for the sensitive nature of some questions, such as those referring to wanting to harm myself, and being bothered by unusual thoughts, beliefs or experiences. Interviewers noted that some items, particularly 15, 19, 21, 22, $23,24,25,26$, and 28, occasionally triggered feelings or memories of distress, and suggested that for these items interviewers allow participants a little more time to discuss particular experiences.

\section{DISCUSSION}

This study investigated aspects of the reliability and validity of the WSE-38 in order to develop the scale further for use in supported employment and psychiatric rehabilitation settings. The scale attained good short cycle test-retest reliability or better for 35 items and for the total score, with very good internal consistency, but not a clear internal structure other than as a unidimensional measure. The removal of three items $(6,35$ and 36) reduced the length of the scale to 35 items, which improved its utility. These findings add to the psychometric properties previously reported (Waghorn et al, 2005a; 2007a; 2008). The internal structure was not replicated, although there is support for a unidimensional structure as found previously (Waghorn et al, 2005a). Its use as a single dimension scale is recommended with a focus on individual items for exploring perceived barriers to employment and for generating new interventions based on these experiences.

Evidence was found for the reliability of work-related subjective experiences, a source of idiosyncratic and experiential information which, in theory, taps into the trisection of the person, their mental illness, and their perceived demands of employment. This construct may add explanatory depth to Fabian's (2000) social cognitive career learning theory, provided that knowing about these experiences can make a difference. Once identified, these subjective experiences must be capable of amelioration, and when this is achieved, participation in supported employment, work-related self-efficacy, work performance, and employment status, should increase proportionally. Previous investigations have established a strong and consistent gradient between work-related subjective experiences and vocational sta- 
tus, mediated by work-related self-efficacy (Waghorn et al, 2007a). However, the predictive validity of interventions targeting workrelated subjective experiences, as a method for enhancing employment outcomes in supported employment, is yet to be established.

Further caveats to these results are the administration challenges reported by interviewers, who noted the potential for some items to trigger mild reactions in clients. These comments are important and suggest that although the measure proved reliable when used as a telephone interview, a personal interview is preferred for efficient administration as well as for preventing and managing possible reactions, even if these are mild or relatively rare. The utility of face to face interviews for collecting this type of personal information is well known and has been documented previously (Ryan et al, 2009).

Face to face interviews better suit a conversation about subjective experiences, especially when a two step process is required. First the candidate experiences are read to the person over the telephone and clients are asked if they have also had that or a similar experience in the past six months. The second step involves encouraging and helping each client to make a Likert-type rating of the extent that that the recognised experience, when present, impacts on working. Interviewers reported that of the set of measures examined, this one was the most challenging to conduct by telephone. Difficulties were attributed to the lack of visual cues available to check client understanding and recognition of candidate experiences, and help maintain client attention throughout the interview. Face to face interviews also enable clients to read the information as well as hear it, which can help shorten the interview duration. In summary, these caveats suggest that the initial administration ought to be by face to face interview, but that subsequent discussion of particular experiences and strategies can continue by telephone when this is more convenient for clients.

Due to the clinical information triggered by this measure, it is only recommended for use by trained rehabilitation professionals, or by mental health team members as a way of supporting an integrated disability employment programme. The tool is not recommended for use by employment specialists with little or no psychiatric training, unless sufficient additional training is provided to equip interviewers with the knowledge and skills needed to discuss relevant clinical-employment issues and identify signs of adverse client reactions and client distress that may need immediate clinical attention.

These caveats suggest that the way the measure is applied to develop interventions will be important and will require some formal training, even for health professionals. Although there are no formal links between this measure and the strength-based approach (Rapp et al, 2005), a strengthsbased focus is needed to guide the way the tool is used to explore subjective experiences while building and not damaging client confidence. A strength-based approach will prevent its possible misuse by focusing too much on the psychopathology associated with work-related subjective experiences. Each subjective difficulty may represent an important opportunity for intervention and appears linked to diagnostic symptoms. However, a strength-based approach is needed to maintain a focus on the person's numerous strengths that ought to become evident as the measure is completed. The focus ought to be on the experiences which the person already manages well, that have little or no effect on their perceived ability to work, when that experience is present. Six principles of strengths based practice (Rapp et al, 2005) are relevant to the administration of this measure.

Only the experiences that the client agrees represent a barrier to their preferred type of employment need to become an intervention goal. The experiences that are managed well can be used to identify client resources and strategies that are already in use. In addition, the work environment and the employer can be recruited as sources of information and help. Very specific goals can be identified which target the amelioration of specific experiences and which develop a sense of hopefulness and confidence in the client. All target experiences and suggested strategies can become meaningful choices for the client, who can be regarded as the expert in managing their own work-related subjective experiences.

A possible criticism was considered that a strength-based approach is best applied without any reference to a measure of psychopathology, even if the focus is subjective, work-related, and empowering. However, in applying this measure to date, among 
people with schizophrenia in particular, these experiences are considered real and important, and can lead to new information relevant to generating employment preferences and preferences for particular forms of assistance. It was also found that these experiences are not generated by open ended questions such as 'How does your illness impact on your ability to work?' (Waghorn et al, 2005a). This observation is possibly due to the meta-cognitive impacts of psychosis, in particular the inability to generate detailed and specific verbal information in response to general questions. Encouraging clients to talk about these experiences using a strengths-based approach does not seem to cause new psychological distress and appears more constructive than ignoring them as if they are not real or not relevant to the employment assistance proposed.

Another possible criticism is that these experiences may not be as relevant for people with disorders other than psychotic disorders. However, this has not been the authors' experience in practice, most likely because the item pool was originally selected to systematically sample symptom domains (cognitive, negative, positive, disorganized, social difficulties, medication and drug use; Waghorn et al, 2005) using a wide range of psychopathology and subjective complaint scales as item sources. Similar test-retest reliability and utility was found when using the measure with mainstream

\section{KEY POINTS}

Work-related subjective experiences are non-diagnostic yet capture aspects of personal and illness related information that are perceived to hinder participation in competitive employment.

The revised WSE-35 is best used by trained practitioners in a personal interview setting to initiate discussion of personal experiences that may hinder employment in terms of particular tasks or situations.

- These experiences can then be used to design workplace interventions to improve prospects of success in competitive employment.

- Although developed for use with people with psychiatric disabilities, the WSE-35 can be trialled among clients with other categories of disability.

- Further psychometric investigations are required before the tool is used routinely by either mental health or disability employment services. university students who had normal range scores on the General Health Questionnaire (Waghorn et al, 2008). These students were able to reliably identify subjective experiences, even when some items were clearly directed at the experience of psychotic symptoms. The students seemed to have no difficulty understanding these items (e.g. bothered by unusual beliefs; bothered by unusual experiences) and identified a rich range of experiences from which particular strengths and difficulties could be identified for use in designing interventions for more troublesome experiences.

The measure is intended to bypass service provider preconceptions about how particular diagnostic symptoms may, or may not, produce barriers to employment. A typical conversation with a client might proceed as follows. The client may have indicated 'Trouble recognising faces' (Item 35) as a subjective experience perceived to impact on their ability to work. The employment specialist might then ask the person to tell them more about that experience, how it might be a problem at work, and how they have managed this experience in the past or in other settings. The client then ought to be asked whether they want any help to manage that experience in a particular employment context. For example, if the client's job preference was to work as a classroom teacher's aide, a series of strategies might be developed to help the client learn and remember children and other teachers' names. A backup script might also be written and rehearsed for use when a particular person's name is forgotten, as a specific social skill. These experiences can also be discussed with the client's mental health professional to identify whether the experience can also be addressed as part of the treatment plan.

\section{CONCLUSIONS}

These results add to the accumulating evidence for the reliability and validity of the work-related subjective experiences construct. The measure is recommended for research purposes in community mental health services where effective supported employment programmes are established. A strengths-based application is recommended to design interventions targeting the specific subjective experiences that represent barriers to progress. Sensitivity to change, utility 
for generating interventions that help, and predictive validity with respect to employment outcomes, require further investigation before this measure is recommended for routine use in mental health and supported employment services. IJTR

Conflict of interest: none

Acknowledgements: This study was supported by QCMHR and the Australian Government Department of Health and Ageing. We thank the participants and the research team from the Brisbane site of the NIMH funded Molecular Genetics Initiative for Schizophrenia Part 2.

American Psychiatric Association (1994) Diagnostic and Statistical Manual of Mental Disorders. 4th edn. American Psychiatric Association, Washington DC

Bandura A (1997) Self-efficacy the Exercise of Control. WH Freeman and Company, New York

Bond GR, Drake RE, Becker DR (2008) An update on randomized controlled trials of evidencebased supported employment. Psychiatr Rehabil J 31(4): 280-90

Cohen JA (1960) A coefficient of agreement of nominal scale. Education and Psychological Measurement 20(1): $37-46$

Cronbach LJ (1990) Essentials of Psychological Testing 5 th edn. Harper Collins, New York

Fabian ES (2000) Social cognitive theory of careers and individuals with serious mental health disorders: Implications for psychiatric rehabilitation programs. Psychiatr Rehabil J 23: 262-9

Fleiss JL, Cohen J (1973) The equivalence of weighted kappa and the intraclass correlation coefficient as measures of reliability. Educational and Psychological Measurement 33(3): 613-9

Harris M, Gladman B, Hennesey N, Lloyd C, Mowry B, Waghorn G (2010) The reliability of an educationrelated self-efficacy scale for people with psychiatric disabilities. Community Ment Health $J$ [Epub ahead of print]

Hatfield AB (1989) Patients' accounts of stress and coping in schizophrenia. Hosp Community Psychiatry 40(11): 1141-5

Jablensky A, McGrath J, Herrman H et al (1999) National Survey of Mental Health and Wellbeing. Report 4. People Living with Psychotic Illness: An Australian Study. Australian Government Department of Health and Ageing, Canberra

Landis JR, Koch GG (1977) The measurement of observer agreement for categorical data. Biometrics 33(1): 159-74

Leckman JF, Sholomskas D, Thompson WD, et al (1982) Best estimate of lifetime psychiatric diagnosis: a methodological study. Arch Gen Psychiatry 39(8): 879-83

Liddle FP, Barnes TRE (1988) The subjective experience of deficits in schizophrenia. Compr Psychiatry 29(2): $157-64$

MacCallum RC, Widaman KF, Zhang S, Hong S (1999) Sample size in factor analysis. Psychological
Methods 4: 84-99

Nurnberger JI Jr, Blehar MC, Kaufmann CA et al (1994) Diagnostic Interview for Genetic Studies: rationale, unique features, and training: NIMH Genetics Initiative. Arch Gen Psychiatry 51(11): 849-59

Palm KM, Strong DR (2007) Using item response theory to examine the White Bear Suppression Inventory. Personality and Individual Differences 42(1): 87-98

Preacher KJ, MacCallum RC (2002) Exploratory factor analysis in behavior genetics research: Factor recovery with small sample sizes. Behavior Genetics 32(2): 153-61

Rapp CA, Saleebey D, Sullivan WP (2005) The future of strengths-based social work. Advances in Social Work 6(1): 79-90

Rey JM, Plapp JM, Stewart G et al (1987) Reliability of the psychosocial axes of DSM-III in an adolescent population. Br J Psychiatry 150: 228-34

Ryan F, Coughlan M, Cronin P (2009) Interviewing in qualitative research: The one-to-one interview. International Journal of Therapy and Rehabil 16(6): 309-14

Sanders AR, Duan J, Levinson DF et al (2008) No significant association of 14 candidate genes with schizophrenia in a large European ancestry sample: implications for psychiatric genetics. Am J Psychiatry 165(4): 497-506

Shrout PE, Fleiss JL (1979) Intraclass correlations: Uses in assessing rater reliability. Psychol Bull 86(2): 420-7

Sim J, Wright CC (2005) The Kappa statistic in reliability studies: Use, interpretation, and sample size requirements. Phys Ther 85(3): 257-68

Stewart G, Sara G, Harris MG et al (2010) A brief measure of vocational activity and community participation: Psychometric properties of the APQ6. Aust N Z J Psychiatry 44(3): 258-66

Thorndike RM (2001) Reliability. In: Bolton BF ed. Handbook of Measurement and Evaluation in Rehabilitation. 3rd edn. Aspen, New York

Waghorn G, Chant D, King R (2005a) Work-related subjective experiences among community residents with schizophrenia or schizoaffective disorder. Aust $N Z J$ Psychiatry 39(4): 88-99

Waghorn G, Chant D, King R (2005b) Work-related self-efficacy among community residents with psychiatric disabilities. Psychiatr Rehabil J 29(2): 105-13

Waghorn G, Chant D, King R (2007a) Work-related subjective experiences, work-related self-efficacy, and career learning among people with psychiatric disabilities. American J Psychiatr Rehabil 10: 275-300

Waghorn G, Chant D, King R (2007b) Classifying socially-valued role functioning among community residents with psychiatric disorders. American $J$ of Psychiatr Rehabil 10(4): 185-221

Waghorn G, Lloyd C, Mackenzie-Ross A, Schembri S (2008) Generalizability of a measure of work-related subjective experiences for people with psychiatric disabilities. J Rehabil 74: 27-33

Walter SD, Eliasziw M, Donner A (1998) Sample size and optimal designs for reliability studies. Stat Med 17(1): 101-10 
T he authors of this article rightly appreciate that patients with major mental illness can and want to work. One of the barriers to successful and fulfilling employment can be an individual's work-related subjective experiences, a scale to measure this being the subject of this article. The authors appropriately regard the patient as 'the expert in managing [these] work-related subjective experiences.' Indeed, patients can and should be encouraged to take an active role in managing their illness, rather than identify themselves as passive victims of it and helpless to do anything about it.

\section{Different patient outlooks}

Not every patient with major mental illness, however, assumes this active role; in fact, patients with major mental illness are not homogeneous in many respects. One of the key distinguishing characteristics relevant to this article is the desire to work, which clinicians cannot assume their patients have, but rather is a threshold issue that requires scrutiny before patients are referred for vocational rehabilitation. While injurious work-related subjective experiences can have a negative 'feedback' effect on the desire to work, lack of desire still must be recognized and understood as a key determinant - in its own right of a patient's joblessness.

To assert that some patients do not want to work is to appreciate that mental illness does not immunize against feelings, preferences, and choices people without mental illness have. Just as some

\section{Just as some people - despite having no impediment to working - simply have no inter- est in doing so, some patients - including those with a minimal or no obstacle to employment - have no desire to procure a job."}

people - despite having no impediment to working - simply have no interest in doing so, some patients - including those with a minimal or no obstacle to employment - have no desire to procure a job. Despite this lack of interest and because of pressure from family or treaters, such patients might present themselves to rehabilitation professionals nonetheless. These patients need to be identified early, their lack of desire recognized and understood, and a differential diagnosis for this lack of desire constructed.

\section{Causes of lack of desire to work}

One cause may be that the individual is simply lazy. This laziness may or may not be fostered by the availability of disability payments. While this view might be branded cynical, it is no less possible or accurate in some instances. The remedy for this - if there is one - is likely to be societal, not psychiatric.

Another cause of lack of desire to work may be demoralization from past workrelated subjective (or objective) experiences; such a person has simply given up. The treatment here is to give such patients time and space to talk about and thus integrate their past experiences, and consequently reclaim the ambition and desire to work they once had.
Another cause may be avoidance of narcissistic injury. This group of patients has some impediment that renders certain jobs unattainable and they are unwilling to take jobs they feel are beneath them or not good enough for them. In these instances, what curtails their employment is not a symptom or an on-the-job experience but an anticipated 'narcissistic blow' they would prefer to avoid. These patients do not suffer from a lack of desire to work as much as from a desire to work only certain jobs. The quick fix is to appeal to such patients' positive self-regard by encouraging them to see that working is more advantageous than not and that, if they do well, they can move 'up' to a more desirable job.

\section{John Querques, M.D.}

Associate Director,

Psychosomatic Medicine-Consultation

Psychiatry Fellowship Program,

Massachusetts General Hospital, Boston,

Massachusetts; and,

Assistant Professor of Psychiatry,

Harvard Medical School, Boston,

Massachusetts, USA

JQUERQUES@PARTNERS.ORG
$\mathrm{P}$ eople who experience mental ill health all too commonly face unemployment, disrupted education or workforce participation, discrimination and other employmentrelated barriers that restrict their job prospects and career options. Yet, there is ample research evidence to demonstrate that, with the right supports in place, people who experience mental ill health can and do succeed in employment (Grove et al, 2005; Bond et al, 2008), so that access to effective support is crucial to improving their employment and career opportunities.
The underlying idea behind this study is to create an instrument that could help mental health professionals to tailor their interventions towards better addressing employment restrictions.

\section{This article}

The authors suggest career development theory as a frame, within which to identify personal, illness-related and environmental variables that impact not only the securing and keeping of jobs, but also the building of satisfying careers. They introduce subjective experience as one variable of importance in career development, and focus on the measurement of subjective experiences that might impact managing workrelated situations. Hence, this article reports the empirical testing of the Work-related Subjective Experiences Scale (WSE-38), a tool developed by the authors. The WSE-38 comprises a list of descriptors for behaviours and experiences that might potentially be troublesome in many everyday life situations. These items are described as derived from self-reports of employment experiences, but no further details are given and the WSE-38 appears less 
specifically work-related than its name suggests. As a result, the WSE-38 could potentially have wider applicability for exploring and identifying the difficulties that individuals themselves experience when engaged in, or seeking to engage in wide-ranging activities of everyday life.

\section{Possible uses for WSE-38}

Of particular note, this tool might be used to guide conversations with persons who experience mental ill health about subjective experiences that are, or could be troublesome, so as to develop relevant strategies for use in their particular workplaces. Used within a strengths-focused framework, as recommended, and to collaboratively engage with persons who experience mental ill health, the WSE-38 may prove especially useful in supported employment programmes to aid effective job matching, identify relevant workplace adjustments, and explore strategies for drawing on natural supports within and beyond the workplace.

\section{There is ample research evidence to demonstrate that, with the right supports in place, people who experience mental ill health can and do succeed in employment."'}

Enhancing these aspects of supported employment programmes has been suggested as a strategy to better support individuals who experience mental ill health to retain employment (Kirsh et al, 2005; Bond et al, 2008). Thus, a worthwhile next step in exploring the utility of the WSE-38 might include its trial for these purposes in supported employment programmes. In addition, no information was presented about participants' employment experience or status in this study, yet limited recent experience of work situations might account for the concerns raised about how WSE-38 questions were phrased, or understood. To address these issues, future studies of WSE-38 also need to actively involve job seekers and work- ers with experience of mental ill health and employment.

Bond GR, Drake RE, Becker DR (2008) An update on randomized controlled trials of evidence-based supported employment. Psychiatr Rehabil J 31(4): 280-90

Grove B, Secker J, Seebohm P (Eds.) (2005) New thinking about mental health and employment. Radcliffe Publishing, Abingdon

Kirsh B, Cockburn L, Gewurtz R (2005) Best practice in occupational therapy: Program characteristics that influence nesses. Can J Occup Ther 77(5) 265-79

\section{Ellie Fossey, DipCOT(UK), MSc, PhD}

Senior Lecturer, and

Postgraduate Courses Co-ordinator,

School of Occupational Therapy,

La Trobe University,

Bundoora, Victoria,Australia

e.fossey@latrobe.edu.au vocational outcomes for people with serious mental ill-
D esigning a psychometric instrument is always a difficult task; yet, the authors have done well in creating the work-related subjective experiences measure. A number of studies have demonstrated that there are considerable benefits of employment for individuals with mental health needs (Lahelma, 1992; Boardman et al, 2003). Nevertheless, discrimination against individuals who declare any mental health issues is widespread with many desiring paid employment but few being actually employed (DH, 2010; Perkins and Rinaldi, 2002).

\section{The measure}

The exploratory factor analysis of the measure revealed three main components of the scale. The first of these consisted of symptom control and relating to others. This in our own research (Biggs et al, 2010) was a concern that employers and employment agencies putting forward potential employees had with individuals with mental health needs. In other words, how do people with mental health needs relate to those around them, be it customers or colleagues? The second factor concerned with memory

\section{The measure, if used correctly, may aid individu- als seeking employment opportunities."}

and thinking was also highlighted as a concern of performance by employers. Would individuals that had previous or existing mental health issues remember aspects of the job taught to them? The final factor of psychological distress was also highly useful, especially if used in conjunction with a measure such as the general health questionnaire. Further research with different participants could see modeling of the data using a confirmatory factor analysis. However, using the measure as a whole is likely to give an indication of how to rehabilitate those that have a previous or existing psychiatric disorder.

\section{Conclusions}

The work-related subjective experiences measure is a useful addition to the literature. The authors suggestion of its use with trained practitioners in either clinical or occupational psychology is to be applauded. The measure, if used correctly, may aid individuals seeking employment opportunities. This, as the literature has shown, is important to individuals with previous or existing mental health needs. It is also important for society to give employment to these individuals.

Biggs D, Hovey N, Tyson PJ, MacDonald S (2010) Employer and employment agency attitudes towards employing individuals with mental health needs. I Ment Health 19(6): 505-16

Boardman J, Grove B, Perkins R, Shepherd G (2003) Work and employment for people with psychiatric disabilities. $\mathrm{Br}$ J Psychiatry 182(6): 467-8

Department of Health (2010) New Horizons: A shared vision for mental health. Online. http://tinyurl.com/yaezk9a (accessed 17 February 2010)

Lahelma E (1992) Unemployment and mental well being: elaboration of the relationship. Int J Health Serv 22(2): 261-74

\section{Dr David Biggs, CPsychol AFBPsS}

Programme Director, Occupational Psychology

HPC Registered Occupational Psychologist Department of Natural and Social Sciences University of Gloucestershire,

Gloucestershire, UK

dbiggs@glos.ac.uk 